Mycosphere

\author{
Article - special issue \\ Doi 10.5943/mycosphere/si/1b/4
}

Copyright (c) Guizhou Academy of Agricultural Sciences

\title{
Two new species of Spencermartinsia (Botryosphaeriaceae, Botryosphaeriales) from China
}

\author{
Zhang $\mathbf{M}^{1}$, He $\mathbf{W}^{1}$, Wu JR ${ }^{2}$ and Zhang $\mathbf{Y}^{3}$ \\ ${ }^{I}$ Beijing Key Laboratory for Forest Pest Control, Beijing Forestry University, Beijing 100083, PR China. \\ ${ }^{2}$ Key Laboratory of Biodiversity Conservation in Southwest China, State Forestry Administration, Southwest Forestry \\ University, Kunming 650224, China. \\ ${ }^{3}$ Institute of Microbiology, P.O. Box 61, Beijing Forestry University, Beijing 100083, PR China.
}

Zhang M, He W, Wu JR, Zhang Y 2016 - Two new species of Spencermartinsia (Botryosphaeriaceae, Botryosphaeriales) from China. Mycosphere 7(7), 942-949, Doi 10.5943/mycosphere/si/1b/4

\begin{abstract}
Spencermartinsia is a genus in Botryosphaeriaceae characterized by brown, 1-septate ascospores with an apiculus at either end, and usually found on woody hosts. Conidia are twocelled and become brown and 1-septate prior to dehiscence from conidiogenous cells. Based on morphological characteristics and phylogeny of DNA sequences of the internal transcribed spacer (ITS) region and part of the translation elongation factor $1-\alpha$ (tefl- $\alpha$ ) gene, two new species, namely Spencermartinsia alpina and S. yunnana are described from Yunnan province in China.
\end{abstract}

Key words - Asia - Dothideomycetes - phylogeny - taxonomy

\section{Introduction}

Spencermartinsia A.J.L. Phillips, A. Alves \& Crous was introduced as a separate genus from Dothiorella Sacc. based on its brown, 1-septate ascospores with an apiculus at either end, and was typified by S. viticola (A.J.L. Phillips \& J. Luque) A.J.L. Phillips, A. Alves \& Crous (Phillips et al. 2008). Species of Spencermartinsia can be saprophytes, pathogens and endophytes of various woody plants. Recently, more species have been added to Spencermartinsia, i.e. S. citricola A.J.L. Phillips \& Abdollahz., S. mangiferae Abdollahz., Javadi \& A.J.L. Phillips and S. plurivora Abdollahz., Javadi \& A.J.L. Phillips from Iran, New Zealand, Spain and South Africa (Abdollahzadeh et al. 2014) and S. rosulata F.J.J. Van der Walt, Slippers \& G.J. Marais from South Africa (Slippers et al. 2014) and S. westrale W.M. Pitt, J.R. Úrbez-Torres \& Trouillas from Australia (Pitt et al. 2013). Thus, currently the genus Spencermartinsia includes six species (Mycobank http://www.mycobank.org, April 2016).

In the course of an ongoing survey of Botryosphaeriaceae in China, two undescribed species of Spencermartinsia were obtained from woody plants. In this paper we name and describe these species, and resolve their phylogenetic position within Spencermartinsia.

\section{Materials \& Methods}

\section{Isolates and morphology}

Samples were obtained from dead branches $(2.7-3.1 \mathrm{~cm}$ thick) of Camellia sp., Acer 
buergerianum, Ternstroemia gymnanthera, Poncirus trifoliate and Platycladus orientalis in Yunnan province, China in December 2014. Fresh samples were air-dried at room temperature and studied with an Olympus SZ 61 dissecting microscope without prior incubation. Microscopic observations were made from material mounted in lactic acid. Photomicrographs were taken with a Nikon Coolpix 995 digital camera on a Leitz Orthoplan microscope. Measurements of conidia, paraphyses and conidiogenous cells were made from lactic acid mounts.

Isolations were made from pycnidia on dead or dying wood and transferred to malt extract agar (MEA), and subsequently transferred to synthetic nutrient-poor agar (SNA) with sterilized pine needles to induce sporulation. Isolates were kept at ambient temperatures (about $25-30{ }^{\circ} \mathrm{C}$ ) in the dark to determine colony characteristics.

\section{DNA extraction, PCR amplification and sequencing}

DNA was extracted with CTAB plant genome DNA fast extraction kit (Aidlab Biotechnologies Co, Ltd, Beijing, China) from mycelium grown on MEA. The internal transcribed spacer of rDNA (ITS) was amplified and sequenced with primers ITS1 and ITS4 (White et al. 1990). The translation elongation factor-1a (tefl- $\alpha$ ) was amplified and sequenced with primers EF1-688F and EF1-1251R (Alves et al. 2008). DNA amplification and sequencing followed the protocol of Zhang et al. (2009).

\section{Sequence alignment and phylogenetic analysis}

The combined ITS and tefl- $\alpha$ nucleotide sequences were used to infer the phylogenetic relationships among $S$. alpina and $S$. yunnana and other species of Spencermartinsia by maximum parsimony (MP) and bayesian analyses. Sequences generated were analyzed with other sequences obtained from GenBank (Table 1). A multiple alignment was done on MEGA 5 (Tamura et al. 2011) and prior to the phylogenetic analyses, leading or trailing gaps at the start and end were deleted. For bayesian analysis, the best-fit model of nucleotide evolution $(\mathrm{GTR}+\mathrm{I}+\mathrm{G})$ was selected using the Akaike information criterion (AIC; Posada \& Buckley 2004) in MrModeltest 2.3. The metropolis-coupled Markov Chain Monte Carlo (MCMCMC) approach was used to calculate posterior probabilities (Ronquist \& Huelsenbeck 2003). A preliminary Bayesian inference (BI) analysis using MrBayes revealed that the Markov Chain Monte Carlo (MCMC; Huelsenbeck \& Ronquist 2001) steady state was reached after less than 50,000 generations. A conservative burn-in of 500 trees was chosen and a full analysis of 5,000,000 generations was carried out with sampling every 100 generations. Maximum Parsimony (MP) analysis was conducted in PAUP v. 4.0b10 (Swofford 2002). Trees were inferred using the heuristic search option with 1,000 random sequence additions and tree-bisection-reconnection (TBR) as the branch-swapping algorithm and gaps are treated as missing data. Maxtrees were setup to 50,000, branches of zero length were collapsed and all multiple parsimonious trees were saved. Descriptive tree statistics for parsimony (Tree Length [TL], Consistency Index [CI], Retention Index [RI], Relative Consistency Index [RC] and Homoplasy Index [HI]) were calculated for trees generated under different optimality criteria. Trees were viewed in TREEVIEW (Page 1996). Nucleotide sequences generated in this paper were deposited in GenBank. Trees and alignments were deposited in TreeBase with study ID S19496.

\section{Results}

\section{Phylogenetic analyses}

Phylogenetic analysis of the ITS and tefl- $\alpha$ sequence data comprising 887 bp from rDNA revealed 130 parsimony-informative characters. The outgroup taxon was Neofusicoccum luteum. The heuristic search with random addition of taxa (1,000 replicates) generated a single most parsimonious tree of 214 steps $(\mathrm{CI}=0.864, \mathrm{RI}=0.915, \mathrm{RC}=0.791, \mathrm{HI}=0.136)$. Bayesian analysis resulted in a tree with similar topology. The Bayesian tree (Fig. 1) was selected to explain systematic relationships within Spencermartinsia and revealed the new species introduced in this study, namely Spencermartinsia alpina and S. yunnana. 
Table 1 Details of Spencermartinsia strains and other species considered in this study.

\begin{tabular}{|c|c|c|c|c|c|}
\hline \multirow[t]{2}{*}{ Species } & \multirow[t]{2}{*}{ Strain } & \multirow[t]{2}{*}{ Host } & \multirow[t]{2}{*}{ Origin } & \multicolumn{2}{|c|}{ GenBank Accession no. } \\
\hline & & & & ITS & tef1- $\alpha$ \\
\hline \multirow{2}{*}{$\begin{array}{l}\text { Dothiorella } \\
\text { pretoriensis }\end{array}$} & CMW 36480 & Acacia karroo & Pretoria, South Africa & JQ239405 & JQ239392 \\
\hline & CMW 36481 & A. karroo & Pretoria, South Africa & JQ239406 & JQ239393 \\
\hline D. uruguayensis & UY 672 & Hexachlamis edulis & Paysandu, Uruguay & EU080923 & EU863180 \\
\hline S. alpina & CGMCC 3.18001 & Platycladus orientalis & Yunnan, China & KX499645 & KX499651 \\
\hline \multirow[t]{2}{*}{ S. citricola } & ICMP 16827 & Citrus sinensis & New Zealand & EU673322 & EU673289 \\
\hline & ICMP 16828 & C. sinensis & New Zealand & EU673323 & EU673290 \\
\hline \multirow[t]{3}{*}{ S. mangiferae } & IRAN $1545 \mathrm{C}$ & Mangifera indica & Hormozgan, Iran & KC898223 & KC898206 \\
\hline & IRAN $1546 \mathrm{C}$ & M. indica & Hormozgan, Iran & KC898222 & KC898205 \\
\hline & IRAN $1584 \mathrm{C}$ & M. indica & Hormozgan, Iran & KC898221 & KC898204 \\
\hline \multirow[t]{9}{*}{ S. plurivora } & IRAN 1556C & Citrus sp. & Hormozgan, Iran & KC898226 & KC898209 \\
\hline & IRAN 1538C & C. sempervirens & Hormozgan, Iran & KC898229 & KC898212 \\
\hline & IRAN $1552 C$ & $\begin{array}{l}\text { Casuarina } \\
\text { equisetifolia }\end{array}$ & Hormozgan, Iran & KC898228 & KC898211 \\
\hline & IRAN $1553 \mathrm{C}$ & Malus domestica & Hormozgan, Iran & KC898227 & KC898210 \\
\hline & IRAN $1557 \mathrm{C}$ & Citrus sp. & Hormozgan, Iran & KC898225 & KC898208 \\
\hline & IRAN $1556 \mathrm{C}$ & Prunus armeniaca & Hormozgan, Iran & KC898230 & КC898213 \\
\hline & CJA 257 & Eucalyptus sp. & Hormozgan, Iran & KC898224 & KC898207 \\
\hline & DAR 78869 & Vitis vinifera & Eden Valley, Australia & EU603287 & HM800507 \\
\hline & DAR 78872 & V. vinifera & $\begin{array}{l}\text { Adelaide Hills, } \\
\text { Australia }\end{array}$ & EU603292 & HM800510 \\
\hline \multirow[t]{7}{*}{ S. rosulata } & CBS 121760 & A. karroo & Windhoek, Namibia & EU101290 & EU101335 \\
\hline & CBS 121761 & A. mellifera & Pretoria, South Africa & EU101293 & EU101338 \\
\hline & CMW 25394 & A. karroo & $\begin{array}{l}\text { Northern Cape, South } \\
\text { Africa }\end{array}$ & EU101318 & EU101363 \\
\hline & CBS 121762 & A. mellifera & $\begin{array}{l}\text { Northern Cape, South } \\
\text { Africa }\end{array}$ & EU101319 & EU101364 \\
\hline & CMW 25396 & A. mellifera & $\begin{array}{l}\text { Northern Cape, South } \\
\text { Africa }\end{array}$ & EU101320 & EU101365 \\
\hline & CMW 25397 & A. tortillis & $\begin{array}{l}\text { Northern Cape, South } \\
\text { Africa }\end{array}$ & EU101321 & EU101366 \\
\hline & CMW 25398 & A. tortillis & $\begin{array}{l}\text { Northern Cape, South } \\
\text { Africa }\end{array}$ & EU101322 & EU101367 \\
\hline \multirow[t]{2}{*}{ S. viticola } & CBS 117009 & $V$. vinifera & Vimbodi, Spain & AY905554 & AY905559 \\
\hline & CBS 117010 & V. vinifera & $\begin{array}{l}\text { Sant Esteve } \\
\text { Sesrovires,Spain }\end{array}$ & AY905558 & AY905561 \\
\hline \multirow[t]{3}{*}{ S. westrale } & DAR 80529 & V. vinifera & Upper Swan, Australia & HМ009376 & HM800511 \\
\hline & DAR 80530 & V. vinifera & Upper Swan, Australia & HM009377 & HM800512 \\
\hline & DAR 80531 & V. vinifera & Upper Swan, Australia & НМ009378 & HM800513 \\
\hline \multirow[t]{5}{*}{ S. yunnana } & CGMCC 3.17999 & Camellia sp. & Yunnan, China & KX499643 & KX499649 \\
\hline & CGMCC 3.18000 & Camellia sp. & Yunnan, China & KX499644 & KX499650 \\
\hline & CGMCC 3.17998 & Acer buergerianum & Yunnan, China & KX499646 & KX499652 \\
\hline & CGMCC 3.17997 & $\begin{array}{l}\text { Ternstroemia } \\
\text { gymnanthera }\end{array}$ & Yunnan, China & KX499641 & KX499647 \\
\hline & CGMCC 3.17996 & Poncirus trifoliata & Yunnan, China & KX499642 & KX499648 \\
\hline \multirow{2}{*}{$\begin{array}{l}\text { Neofusicoccum } \\
\text { luteum }\end{array}$} & CBS 110299 & $V$. vinifera & Oeiras, Portugal & AY259091 & AY573217 \\
\hline & CBS 110497 & $V$. vinifera & Portugal & EU673311 & EU673277 \\
\hline
\end{tabular}




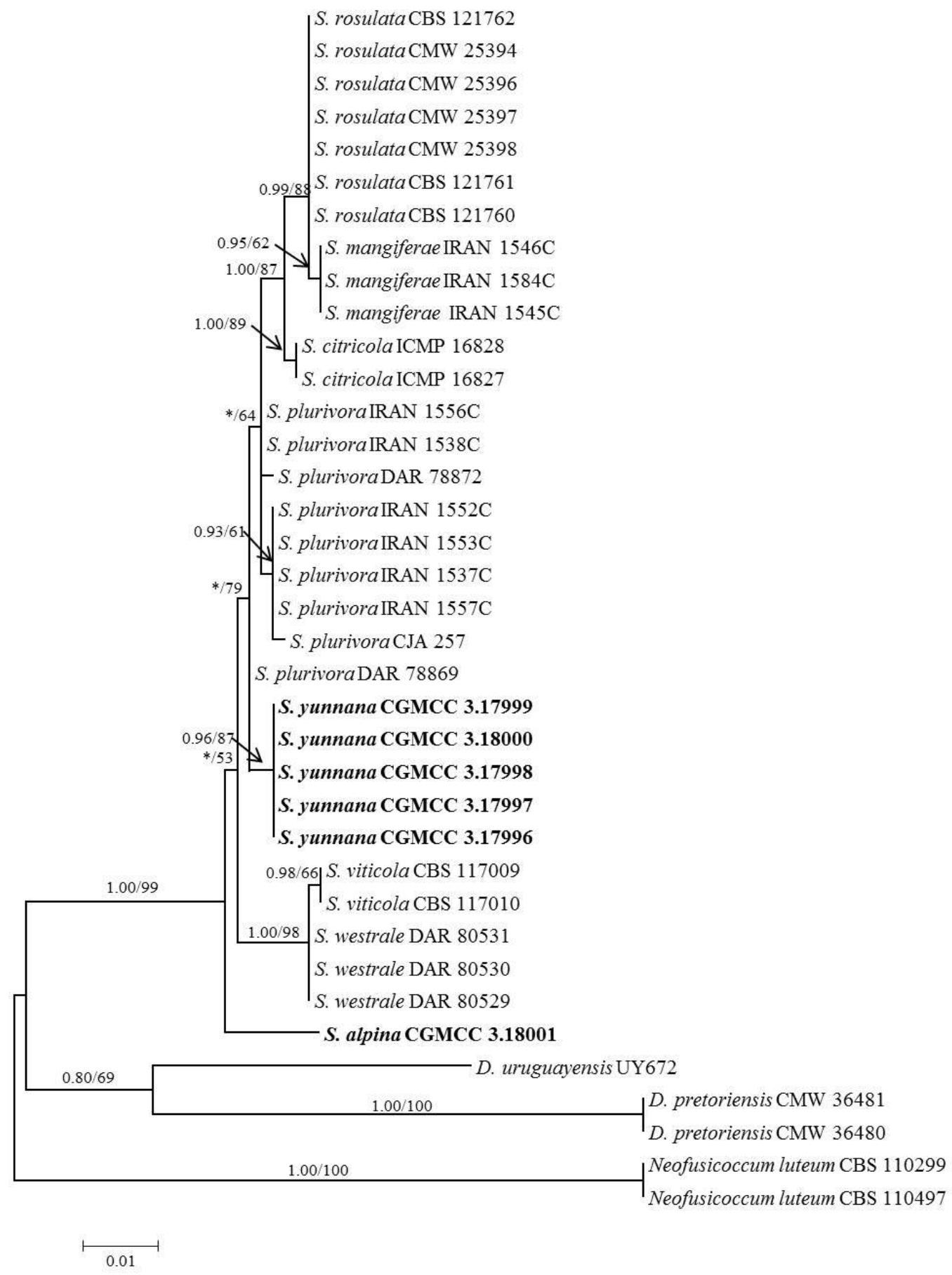

Fig. 1 - Phylogram of the Bayesian analysis based on combined ITS and tefl- $\alpha$ sequences with Neofusicoccum luteum species as outgroup. Numbers above branches indicate posterior probabilities/bootstrap values $(*=$ value less than 0.90$)$.

\section{Taxonomy}

Spencermartinsia alpina Y. Zhang ter., M. Zhang sp. nov.

Fig. 2 MycoBank 817231

Etymology - Latin, alpina, referring to the Zixi mountain where the species was first found.

Conidiogenesis holoblasic, with conidiogenous cells cylindrical to fusiform and slightly utriform, hyaline, thin-walled, smooth, measuring $(5.1-) 6.3-10(-12.4) \times 3-5.2 \mu \mathrm{m}$ and giving rise to periclinal thickenings. Conidia initially hyaline, thin-walled, unicellular (non-septate) becoming thick-walled, dark brown and 1-septate prior to release from the conidiogenous cells, with rounded 
apex or occasionally truncate base measuring (17.2-)19-20.4(-22.4) $\times(7.9-) 8.4-9(-9.7) \mu \mathrm{m}$, with a mean length and width of $19.7 \pm 1.5 \times 8.7 \pm 0.9 \mu \mathrm{m}$, and an average length to width ratio of $2.2 \pm$ 0.2 , slightly constricted at the septa when mature. Conidial wall thickness of $0.6-1.2 \mu \mathrm{m}$, with a mean thickness of $0.9 \mu \mathrm{m}(\mathrm{n}=20)$.

Cultural characteristics - On MEA colonies initially were white with sparse aerial mycelium, and then become denser with white oppressed mycelia radiating outwards, forming small white cottony pycnidial primordia over the surface of the colony after 10 days; turning olivaceous gray gradually, reverse leaden gray.

Cardinal temperatures for growth - Between $5{ }^{\circ} \mathrm{C}$ and $35^{\circ} \mathrm{C}$ with an optimum of $25{ }^{\circ} \mathrm{C}$.

Habitat - Platycladus orientalis.

Specimens examined - CHINA, Yunnan province, Chuxiong city, Zixi mountain forest park (altitude: 2,000 m), from thick branch of dead young tree of Platycladus orientalis, 16 Dec 2014, leg. W. He \& J.R. Wu, det. Y. Zhang (HMAS254733, CGMCC 3.18001).

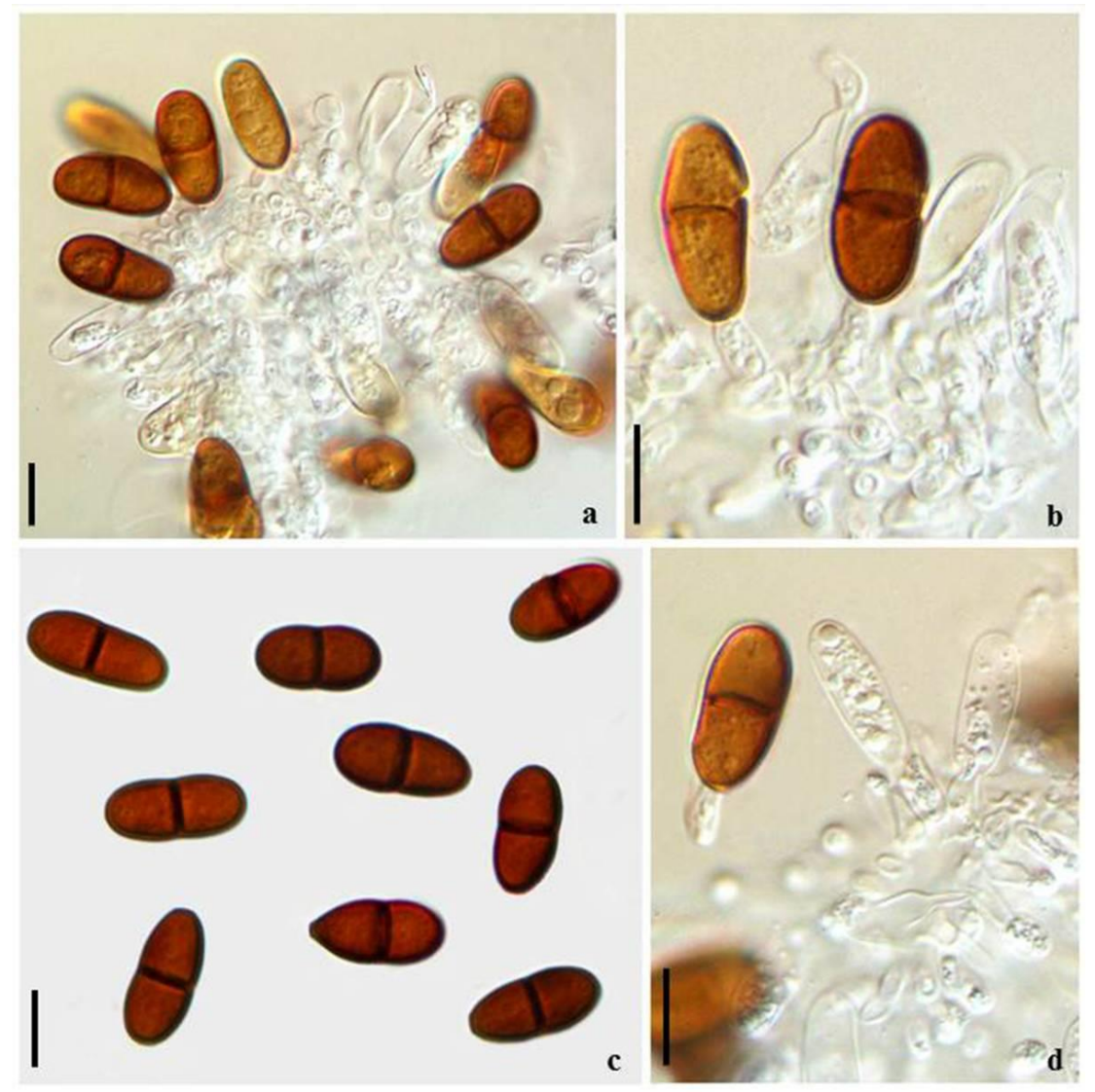

Fig. 2 - Spencermartinsia alpina (HMAS254733). a, b, d Hyaline immature and mature brown 1septate conidia developing on conidiogenous cells. c Mature brown 1-septate conidia. - Bars $=10$ $\mu \mathrm{m}$.

Spencermartinsia yunnana Y. Zhang ter., M. Zhang sp. nov.

Fig. 3 MycoBank 817233 isolated.

Etymology - The epithet yunnana refers to Yunnan province, the place where it was first

Conidiogenesis holoblastic, with conidiogenous cells clavate to cylindrical and slightly utriform, hyaline, thin-walled, smooth, measuring (5.3-)6.5-10.2(-12.6) $\times 3.2-5.4 \mu \mathrm{m}$. Conidia ellipsoid, initially hyaline, thin-walled, non-septate becoming brown and 1-septate, externally smooth, occasionally slightly constricted at the septum with rounded apex and truncate base measuring (18.4-)19.6-21(-22.2) × (8.1-)8.6-9.2(-9.6) $\mu \mathrm{m}$, with a mean length and width of 20.3 $\pm 1.5 \times 8.9 \pm 0.9 \mu \mathrm{m}$, and a mean length to width radio of $2.3 \pm 0.2(\mathrm{n}=30)$. 

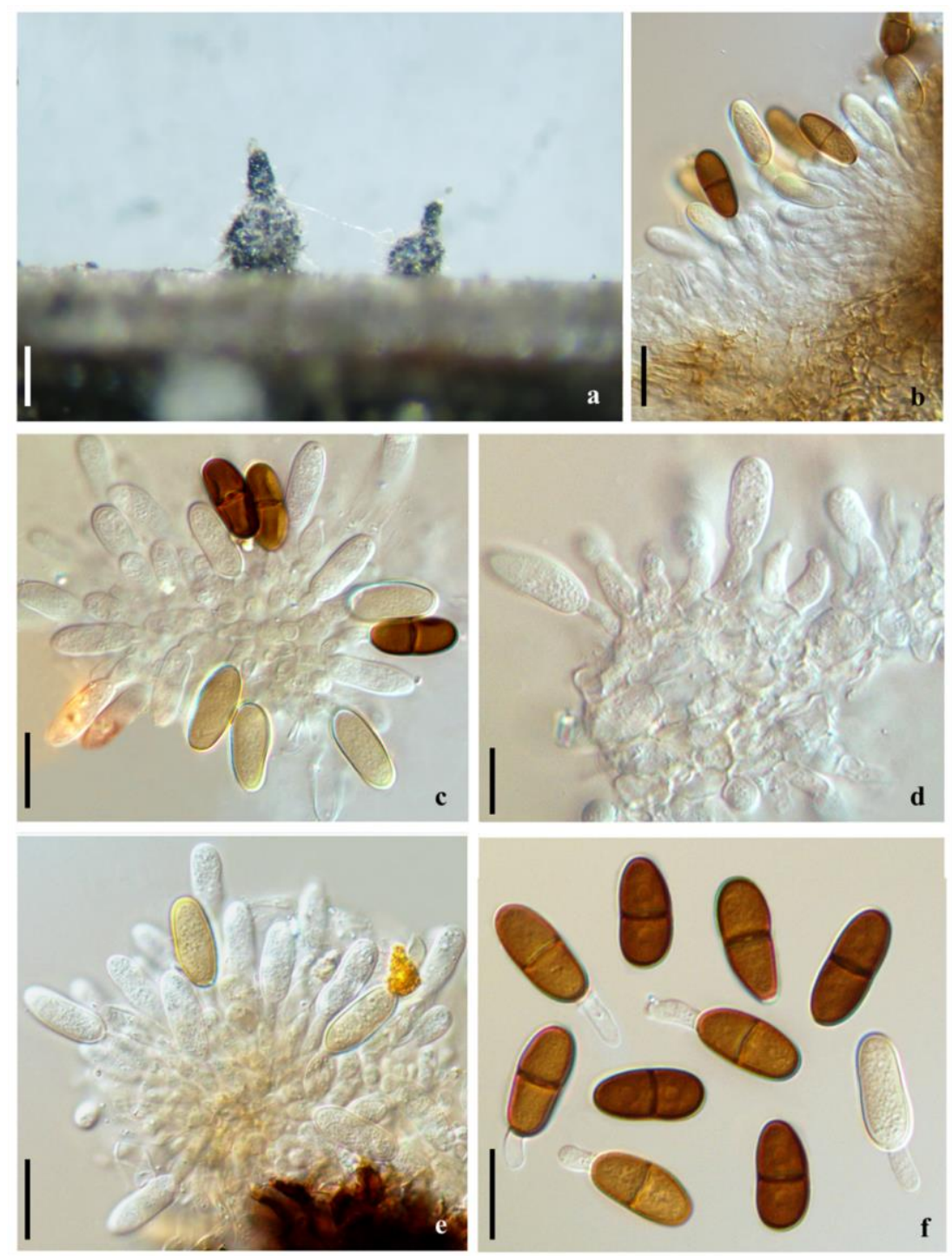

Fig. 3 - Spencermartinsia yunnana (a from CGMCC 3.17999, b-f from HMAS254734). a Conidiomata formed on poplar twigs in culture. b Brown 1-septate conidia attached to the conidiogenous cells. c Hyaline immature conidia attached to conidiogenous cells. d, e Immature aseptate conidia on conidiogenous cells. f Mature conidia. - Bars : $a=1 \mathrm{~mm}, \mathrm{~b}-\mathrm{f}=20 \mu \mathrm{m}$.

Cultural characteristics - On MEA colonies initially were white appressed mycelia radiating outwards, mycelium becoming more flourishing near the margin of the colony. In the center, with white sparse aerial mycelium within 10 days; turning dark slate-blue with olivaceous gray mycelium within 28 days, the reverse leaden gray.

Cardinal temperatures for growth - Between $5{ }^{\circ} \mathrm{C}$ and $35^{\circ} \mathrm{C}$ with an optimum of $25^{\circ} \mathrm{C}$.

Habitat - Camellia sp.

Specimens examined - CHINA, Yunnan province, Chuxiong city, Zixi mountain forest park, from dead branch of Camellia sp., 16 Dec 2014, leg. W. He \& J.R. Wu, det. Y. Zhang (HMAS254734, CGMCC 3.17999).

Additional specimens examined - CHINA, Yunnan province, Chuxiong city, Zixi mountain forest park, from dead branch of Camellia sp., 16 Dec 2014, leg. W. He \& J.R. Wu, det. Y. Zhang (HMAS254735, CGMCC 3.18000); from dead branch of Acer buergerianum, 16 Dec 2014, leg. W. He \& J.R. Wu, det. Y. Zhang (HMAS254736, CGMCC 3.17998); Yunnan province, Kunming city, Kunming arboretum, on the dead twigs of the Ternstroemia gymnanthera, 15 Dec 2014, leg. W. He \& J.R. Wu, det. Y. Zhang (HMAS254738, CGMCC 3.17997); on the dead twigs of the Poncirus trifoliate, 15 Dec 2014, leg. W. He \& J.R. Wu, det. Y. Zhang (HMAS254737, CGMCC 3.17996). 


\section{Discussion}

Spencermartinsia is a cosmopolitan genus and $S$. viticola, the type species, has been reported from four different woody hosts (mostly Vitis vinifera) in China, South Africa, Spain, USA and Uruguay (Abdollahzadeh et al. 2014). In this study, two new species of Spencermartinsia, namely S. alpina and S. yunnana, were collected from Yunnan province, the subtropical area of China.

Only asexual states were observed on the specimens collected. Phylogenetic analyses based on combined ITS and tefl- $\alpha$ sequences indicated that Spencermartinsia alpine and S. yunnana form sibling clades with all other reported species respectively. Morphologically, the dark-brown, thickwalled (mean $=0.9 \mu \mathrm{m}, \mathrm{n}=20$ ) and slightly constricted conidia of $S$. alpina can be readily distinguished from all other reported species of Spencermartinsia. Spencermartinsia yunnana morphologically resembles $S$. magniferae and $S$. viticola, while the conidia of $S$. yunnana are more slender (mean L/W ratio: 2.3) than those of S. magniferae (mean L/W ratio: 2.1) and S. viticola (mean L/W ratio: 1.9 to 2.2) (Pitt et al. 2013, 2015). Apparently the sexual morph of Spencermartinsia viticola tends to occur with its asexual stage (Pitt et al. 2013, 2015). However, the sexual morph of $S$. yunnana was not seen in the present study.

Spencermartinsia yunnana was associated with a wide range of hosts including Camellia sp., Ternstroemia gymnanthera (Theaceae), Acer buergerianum (Sapindaceae) and Poncirus trifoliate (Rutaceae), and was collected from both Zixi mountain forest park (altitude, $2500 \mathrm{~m}$ ) and Kunming arboretum (altitude, $1970 \mathrm{~m}$ ), which may indicate that it is widespread in this region. A single isolate of $S$. alpina was obtained in this study from Platycladus orientalis (Cupressaceae). Its phylogenetic distinction from other species of Spencermartinsia supports its status as a new species.

\section{Acknowledgements}

This study was supported by NSFC Projects of International Cooperation and Exchanges (31461143028), National Natural Science Foundation of China (General Program, 31370063) and National Science and Technology Foundation Project (2014FY210400).

\section{References}

Abdollahzadeh J, Javadi A, Zare R, Phillips AJL 2014 - A phylogenetic study of Dothiorella and Spencermartinsia species associated with woody plants in Iran, New Zealand, Portugal and Spain. Persoonia 32, 1-12.

Alves A, Crous PW, Correia A, Phillips AJL 2008 - Morphological and molecular data reveal cryptic speciation in Lasiodiplodia theobromae. Fungal Diversity 28, 1-13.

Huelsenbeck JP, Ronquist F 2001 - MRBAYES: Bayesian inference of phylogenetic trees. Bioinformatics 17, 754-755.

Page RD 1996 - TreeView: an application to display phylogenetic trees on personal computers. Computer Applications in the Biossciences 12, 357-358.

Phillips AJL, Alves A, Pennycook SR, Johnston PR, Ramaley A, Akulov A, Crous PW 2008 Resolving the phylogenetic and taxonomic status of dark-spored teleomorph genera in the Botryosphaeriaceae. Persoonia 21, 29-55.

Pitt WM, Úrbez-Torres JR, Trouillas FP 2013 - Dothiorella vidmadera, a novel species from grapevines in Australia and notes on Spencermartinsia. Fungal Diversity 61, 209-219

Pitt WM, Úrbez-Torres JR, Trouillas FP 2015 - Dothiorella and Spencermartinsia, new species and records from grapevines in Australia. Australasian Plant Pathol. 44, 43-56.

Posada D, Buckley TR 2004 - Model selection and model averaging in phylogenetics: advantages of Akaike information criterion and Bayesian approaches over likelihood ratio tests. Systematic Biology 53, 793-808.

Ronquist F, Huelsenbeck JP 2003 - MrBayes 3: Bayesian phylogenetic inference under mixed models. Bioinformatics 19, 1572-1574. 
Slippers B, Roux J, Wingfield MJ, van der Walt FJJ, Jami F, Mehl JWM, Marais GJ 2014 Confronting the constraints of morphological taxonomy in the Botryosphaeriales. Persoonia 33, 155-168.

Swofford DL 2002 - PAUP*. Phylogenetic Analysis Using Parsimony (*and Other Methods). Version 4. Sinauer Associates, Sunderland, Massachusetts.

Tamura K, Peterson D, Peterson N, Stecher G, Nei M, Kumar S 2011 - MEGA5: molecular evolutionary genetics analysis using maximum likelihood, evolutionary distance, and maximum parsimony methods. Molecular Biology and Evolution 28, 2731-2739.

White TJ, Bruns T, Lee S, Taylor J 1990 - Amplification and direct sequencing of fungal ribosomal RNA genes for phylogenetics. In: PCR Protocols: a guide to methods and applications (Innis MA, Gelfand DH, Sninsky JJ, White TJ, eds). Academic Press, San Diego, California: 315-322.

www.mycobank.org - 2016

Zhang Y, Wang HK, Fournier J, Crous PW, Jeewon R, Pointing SB, Hyde KD 2009 - Towards a phylogenetic clarification of Lophiostoma / Massarina and morphologically similar genera in the Pleosporales. Fungal Diversity 38, 225-251. 